\title{
A managerial perspective over one year of online education in Romania. A case study at the University of Petroșani
}

\author{
Eduard Edelhauser ${ }^{1 *}$, Lucian Lupu-Dima ${ }^{2}$, and Georgiana Grigoraș ${ }^{3}$ \\ ${ }^{1}$ Head of the Management and Industrial Engineering Department, University of Petroșani, Petroșani, \\ 332006 Romania \\ ${ }^{2}$ Mining Engineering, Surveying and Construction Department, University of Petroșani, Petroșani, \\ 332006, Romania \\ ${ }^{3}$ Management and Industrial Engineering Department, University of Petroșani, Petroșani, 332006 \\ Romania
}

\begin{abstract}
The authors tried to analyse the implication of one year of online education in one of the smallest Romanian university. The analysis was seen as a challenge for the management of a university who was not prepare for e-learning or online education at the beginning of the pandemic crisis. They have made a double investigation, one from the professor perspective and another from the students one. They had investigated the main feature of a standard online or a classical eLearning solution, such as the meeting solution or the videoconference software, the collaborative work such as homework or projects and the testing method or the quizzes from both perspectives. Because the university didn't adopt a unique solution they had made a comparison between the used solutions, and more important they identified the efficiency of the university management in implementing the online education in the pandemic crisis period.
\end{abstract}

\section{Introduction}

University of Petroșani, one of the smallest Romanian universities, was found unprepared by the COVID-19 pandemic, especially regarding the aspects regarding the field of education. The reaction at the management level in this field, online education and eLearning platforms, was not only very slow, but also oscillating. The tools used for online education were diverse, as the decision to select video conferencing software, collaborative solution and testing methods was transferred to teachers and not adopted as a whole. This led to an inhomogeneous method of education, which differed from one teacher to another and which negatively affected students. After 6 months of online education, at the beginning of the $2020 / 2021$ academic year, the university management implemented an eLearning platform developed by an indigenous software developer. This solution was incomplete, as it did not offer the videoconferencing component and did not automatically manage the file of the

\footnotetext{
* Corresponding author: eduardedelhauser@upet.ro
} 
student and the teacher in the classroom. As a result, teachers continued to use different teaching methods.

The authors have more than 10 years of experience in the development and implementation of eLearning and have published more than 15 papers in the field of eLearning. $[1,2,3]$

\section{Theoretical Framework}

The authors goal in this theoretical framework was to demonstrate that, although Zoom is not a collaborative solution for online education, such as Meet or Teams, it has become a widely used and effective tool for meetings and video conferencing. Because the management of the University of Petroșani did not offer their students a collaboration solution, most of the professors had selected Zoom for the online courses and that is why this application is presented.

\subsection{Meeting solution used in online teaching}

Meeting solutions are real-time collaboration applications and associated endpoints that support interactions over a network between participants for team work, presentations, training and webinars. Meeting Solutions Software can help people achieve complete meeting solutions, which enable richness of information and interaction by combining messaging, content and screen sharing, video and audio. Meeting solutions are used in organization as well in the education system, in meeting spaces, at desks, with integrated voice, video, messaging and content sharing. Organizations with complex needs typically have meeting solutions for internal use, for collaboration, learning and internal communication, that are separate from those for external use in sales or marketing. Complete meeting solutions enable richness of information and interaction by combining messaging, content and screen sharing, video and audio.

\subsection{Zoom the most used meeting solution at the University of Petroșani}

The coronavirus has forced people to get creative when it comes to how they communicate with students and teachers. Thanks to the digital age, in communication and also in online education there are plenty of options to stay connected through video conferencing. With so many choices for business video meeting tools available, it's worth looking into the differences and similarities between them. A comparison between the current most popular Cloud-based online video conferencing tools: Zoom, Microsoft Teams and Google Meet is very important, because this meeting solutions were mostly selected by the Romanian teachers for online teaching during the COVID-19 pandemic. The authors have analysed the functionalities and the limitations to see which one suits better for online education.

Google Meet, Zoom and Teams have approximately the same features and tools available to make video conferencing work for business or to be used in the education field. These collaboration and video conferencing tools are very convenient for those working from home or in the office. Google Meet and Microsoft Teams are better for those that really want to be able to collaborate in real-time, because they have full integration with respectively Google Workspace, formerly G Suite, and Office 365 - office suites which several businesses already have available for their employees. Google Meet is also the best choice as an option for video meeting participants to join via dial-in, because Meet doesn't charge an additional call-in fee. Overall, Google Meet is more cost-effective. 
Clearly, there's no obvious winner for the ideal video conferencing tool - the final choice depends on the education business needs and the requirements. [4]

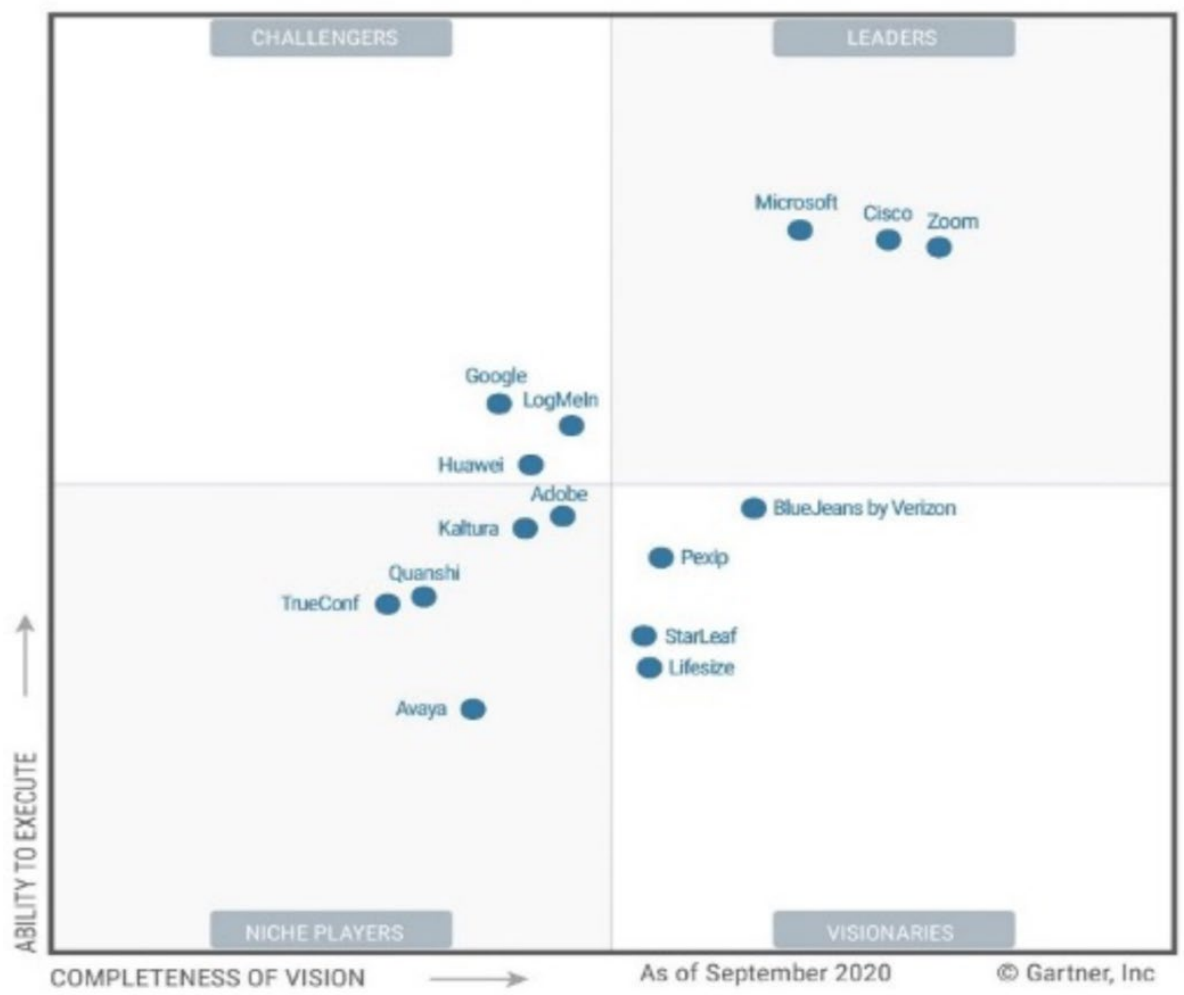

Fig. 1. 2020 Gartner Magic Quadrant for Meeting Solutions [4]

Zoom has been named a leader in the 2020 Gartner Magic Quadrant for Meeting Solutions for the fifth consecutive year as well as a Leader in the 2020 Magic Quadrant for Unified Communications as a Service (UCaaS), Worldwide. The criteria used by Gartner to evaluate companies selected for the Meeting Solutions Magic Quadrant include the ability to satisfy a wide variety of well-established and newly defined virtual meeting scenarios. [5]

\section{Methodology}

\subsection{Population and Sample}

University of Petroșani has a small number of teachers, composed of only 142 professors. The authors selected 125 teachers to answer the questions of the questionnaire, obtaining answers from 80 of them. This situation means a share of $64 \%$ of the selected group. The 125 teachers were selected from the 142, considering that the remaining 17 teachers have a small involvement in teaching activities, such as assistants. Even so, the large number of respondents, 80 professors represent $56 \%$ of the total number of teachers in this small university, so the study is more than representative, probably the most representative study conducted for a small Romanian university in the online period.

The study applied to students, conducted by the authors, was dedicated to students of two faculties of the same university, the Faculty of Sciences and the Faculty of Mines. 2,153 respondents were selected who are in fact the entire students of these two faculties and it is important to mention that the University of Petroșani has only 3 faculties. The reason why 
the authors selected the Faculties of Sciences and Mines is provided by the fact that the didactic activities of the authors involve students only from these two faculties. This choice allowed students to be easily contacted and their responses were in excellent numbers. The 551 responses represent $26 \%$ of the total number of students, so the study is also clearly representative. The students rejecting these two faculties are graduate students in the bachelor's programs - 302, and graduates in the master's programs - 249. The average age of the students was 29 years, and the average age of the graduates was 35 years. Regarding the division of the number of respondents by faculties, 283 students study engineering at the Faculty of Mining, and another 246 students study economics and social sciences at the Faculty of Sciences.

\subsection{Instruments \& Investigation Tools}

The investigation applied to the professors was based on an online questionnaire, dedicated to the professors of the University of Petroșani, a questionnaire composed of 12 questions. These questions were divided into two parts, 6 dedicated to the online education methods used and 6 the impact on students. As already mentioned, the authors receive 80 responses from 125 selected respondents, who responded within a standard time of 8 minutes per interview. The survey took place between January 29, 2021 and February 2, 2021.

The survey of students was based on another questionnaire consisting of 15 questions. In this case, 6 questions were dedicated to the online education methods used and 5 to the impact on students. In this case, the authors receive 551 responses from 2,153 selected respondents. The standard response time was 9 minutes per interview, and the survey took place between January 29, 2021 and February 2, 2021.

\section{Results}

\subsection{Data description and graphical results}

\subsubsection{Investigation 1 - Teachers from the University of Petroșani}

The investigation applied to the 80 professors of the University of Petroşani allowed the authors to present the results of the answers offered to the six questions dedicated to the online education methods used by teachers. 


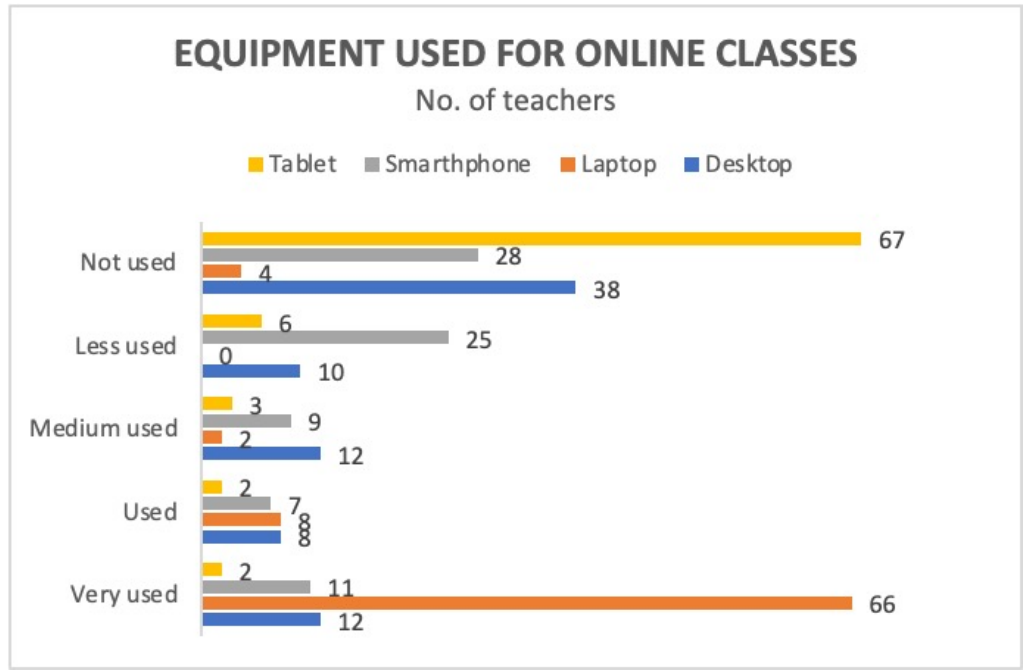

Fig. 2. Hardware equipment used to run the online courses (Answers obtained by choosing the degree of use for each option)

Analysing the answers received, it is found that the most used hardware equipment for online courses are laptops for professors at the University of Petroșani, 82\% of them preferring this versatile equipment. It is no coincidence that this option is correlated with the largest increase in laptop sales in the last 10 years, by $28 \%$ during the COVID-19 pandemic. Over the same period, desktop sales fell $26 \%$. Smartphones are not the favourite equipment of teachers. An explanation for this is provided by the limitations of mobile devices for online teaching, for the preparation of course materials. They can only be used to attend online courses. In this context, it is also relevant that sales in the market decreased in 2020 by $20 \%$ for smartphones.

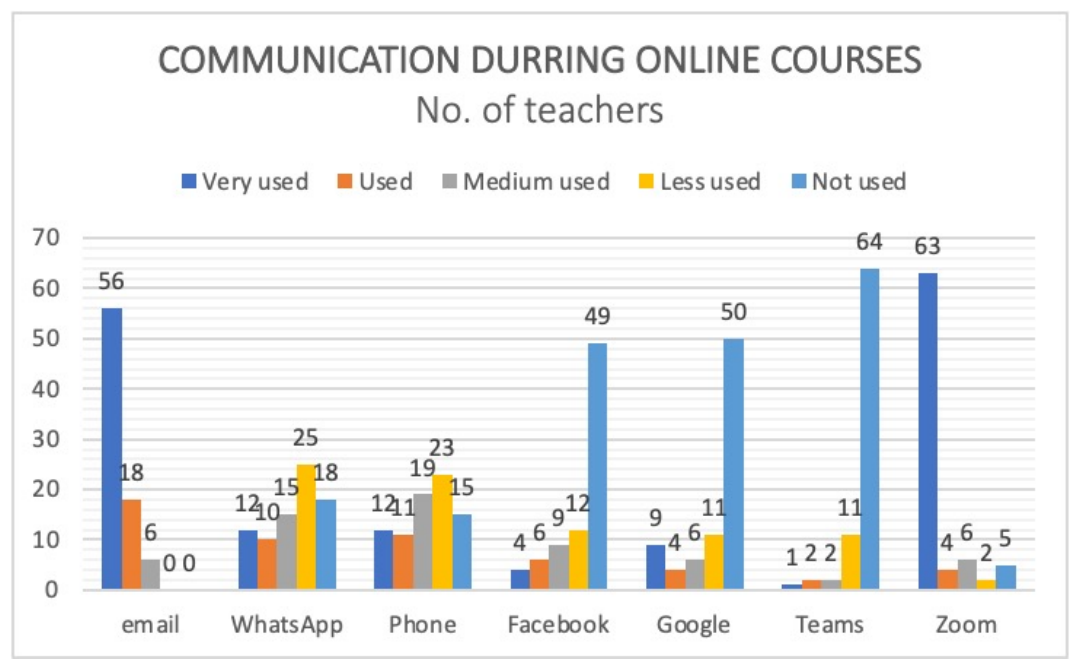

Fig. 3. Method of communication used by teachers to keep in touch with students during COVID-19 pandemic (Answers obtained by choosing the degree of use for each option)

In academic education, as opposed to primary and secondary education, e-mail is a widely used and effective tool for online communication. The preferred meeting tool for members of the University of Petroșani is Zoom. It is also found that Facebook groups or other social 
media tools, used mainly by students and teachers before the pandemic for communication, have dropped dramatically in their preference.

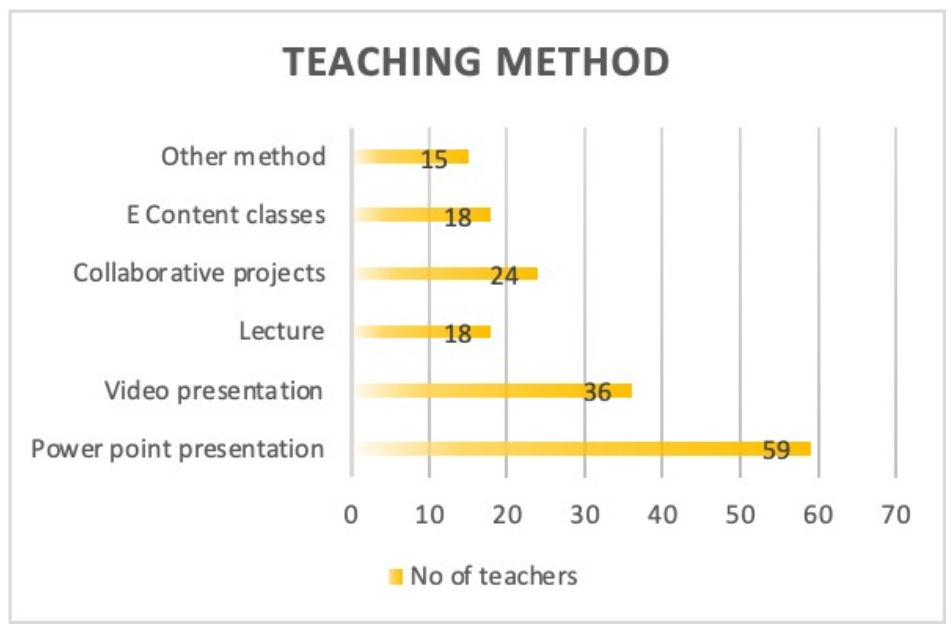

Fig. 4. Teaching method used during COVID-19 pandemic at UPET by teachers

Unfortunately for an academic institution, collaboration projects and e Content methods were used in a small percentage, only $24 \%$.

\section{VIDEOCONFERENCE SOFTWARE}

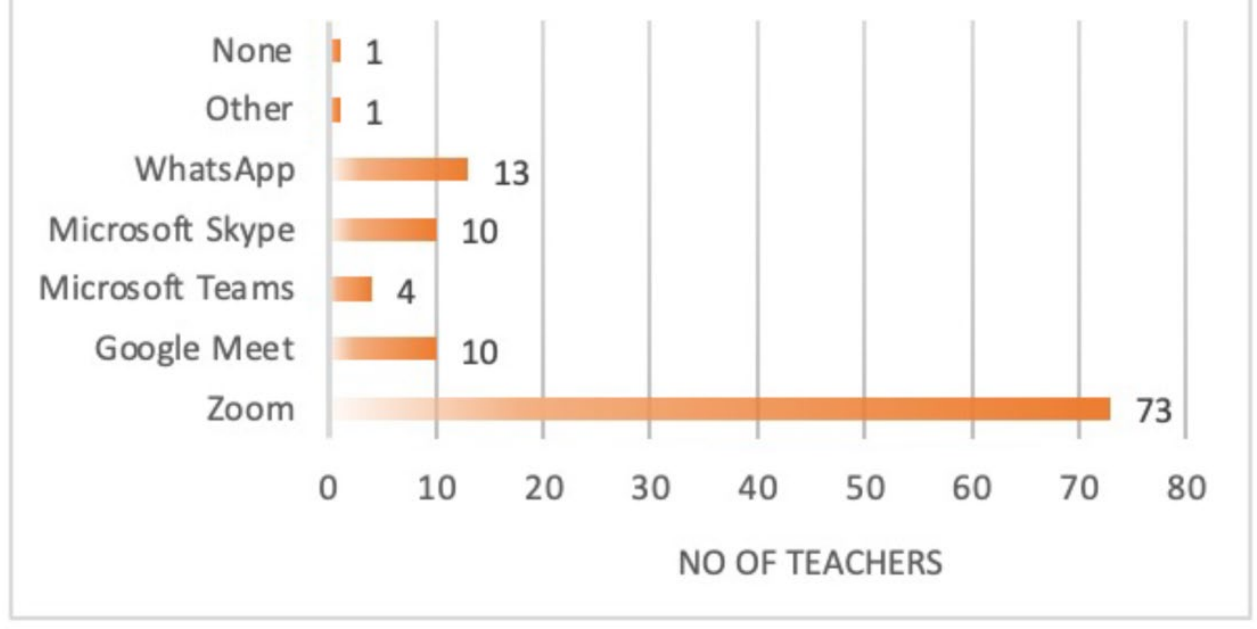

Fig. 5. Video conferencing application - meeting software - used for teaching during COVID-19 pandemic at UPET by teachers

The passage of time has not been used effectively by the board of directors of the University of Petroșani and even though a semester has already passed online, the management has not selected a unique software for meeting conferences. This hesitant option allowed the teachers' choices not to be unitary and this situation unpleasantly affected the students. It is found that even if over $90 \%$ opted for Zoom, the other meeting solution was used. 


\section{HOMEWORK TRANSMISSION}

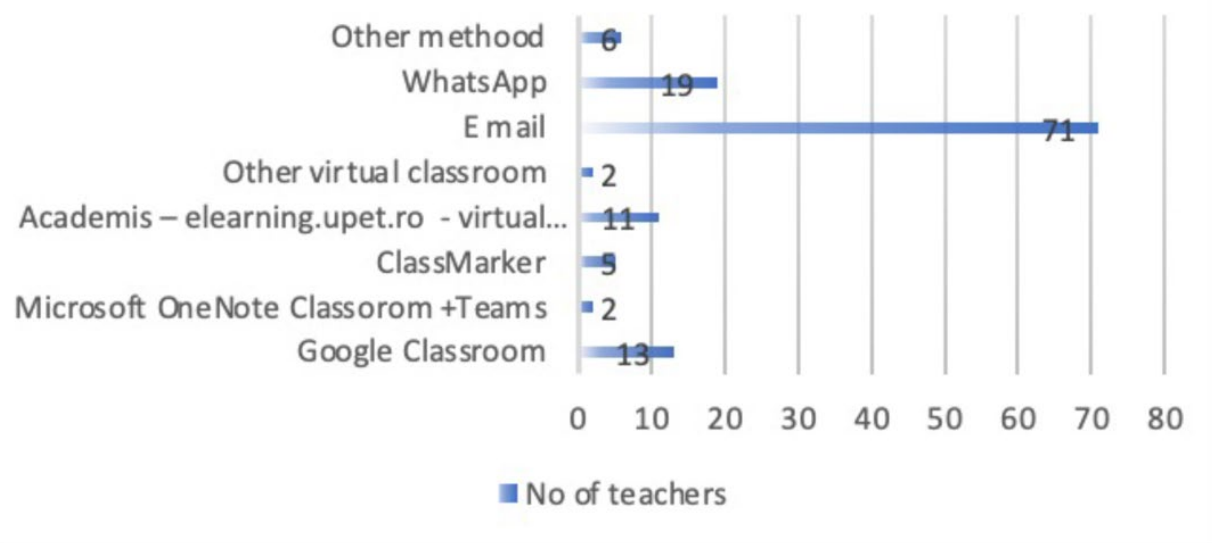

Fig. 6. Homework or projects transmission method used during COVID-19 pandemic at UPET by teachers

In the new academic year, for the autumn semester of the academic year 2020/2021, the University of Petroșani has implemented a weak eLearning platform. It was developed by a native software developer and is called Academis. Academis does not include an online meeting solution, has a rudimentary test module and does not have a self-registration attendance module. as a result of these shortcomings, teachers' choice of homework or project submission remained e-mail for $89 \%$ of them. Academis was used by only $13 \%$ of university professors.

\section{TESTING METHOD (QUIZZES)}

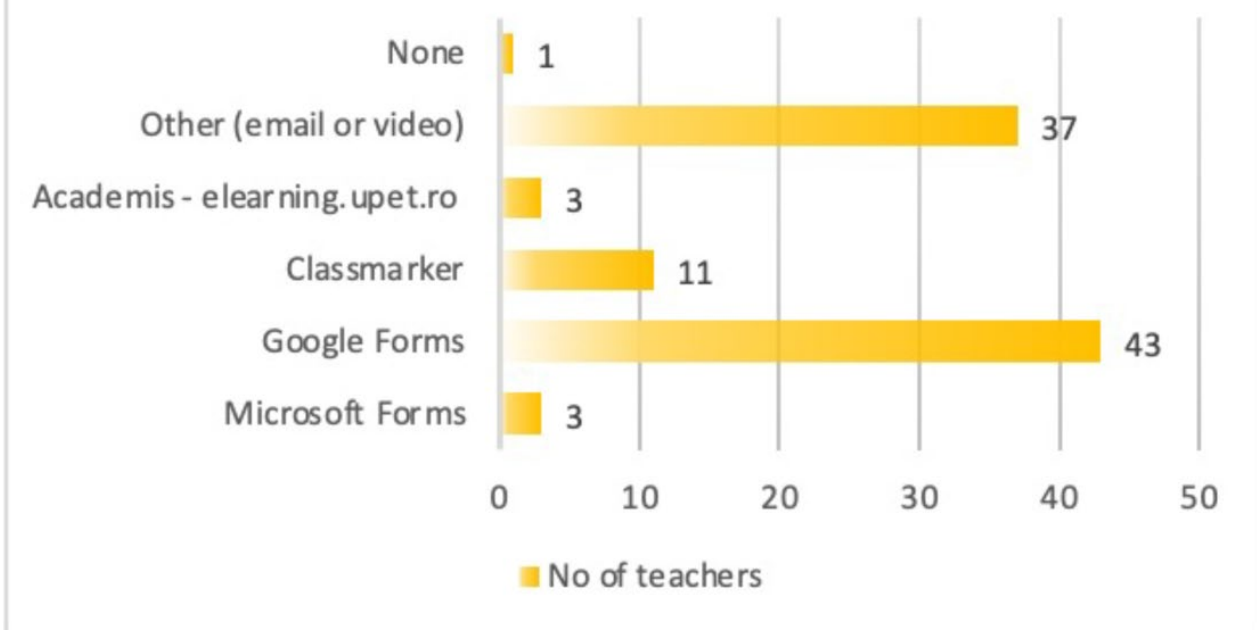

Fig. 7. Testing or examination method used during COVID-19 pandemic at UPET by teachers 
Regarding testing, Quizzes were used as a testing method for $61 \%$ of the teachers. Teachers have used various platforms that have implemented this testing system, such as Google, Class Marker or Microsoft. Homework or project submission by e-mail was used by $38 \%$ of teachers.

\subsubsection{Investigation 2 - Students from the University of Petroșani}

The survey of students, which led to 551 responses, allowed the authors to present the results of four questions dedicated to online education methods applied by teachers.

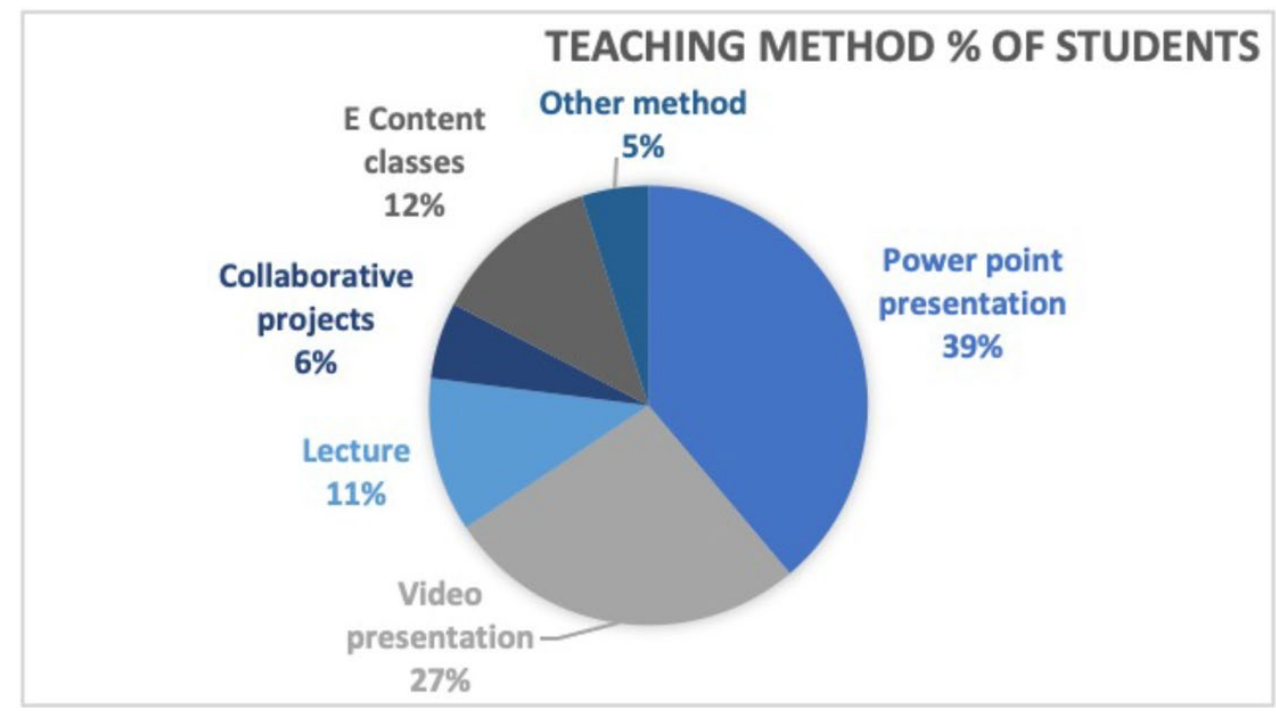

Fig. 8. Teaching method used from the student point of view

In COVID-19 Age University of Petroșani, students receive courses from their professors specific to classical teaching methods, especially PowerPoint presentations that can be easily presented to students through the screen sharing option of the meeting software used. From the students' perspective, e Content projects and methods were used in a very small percentage - $18 \%$. Surprisingly, teachers say that these methods are used in a moderate level $-24 \%$. 


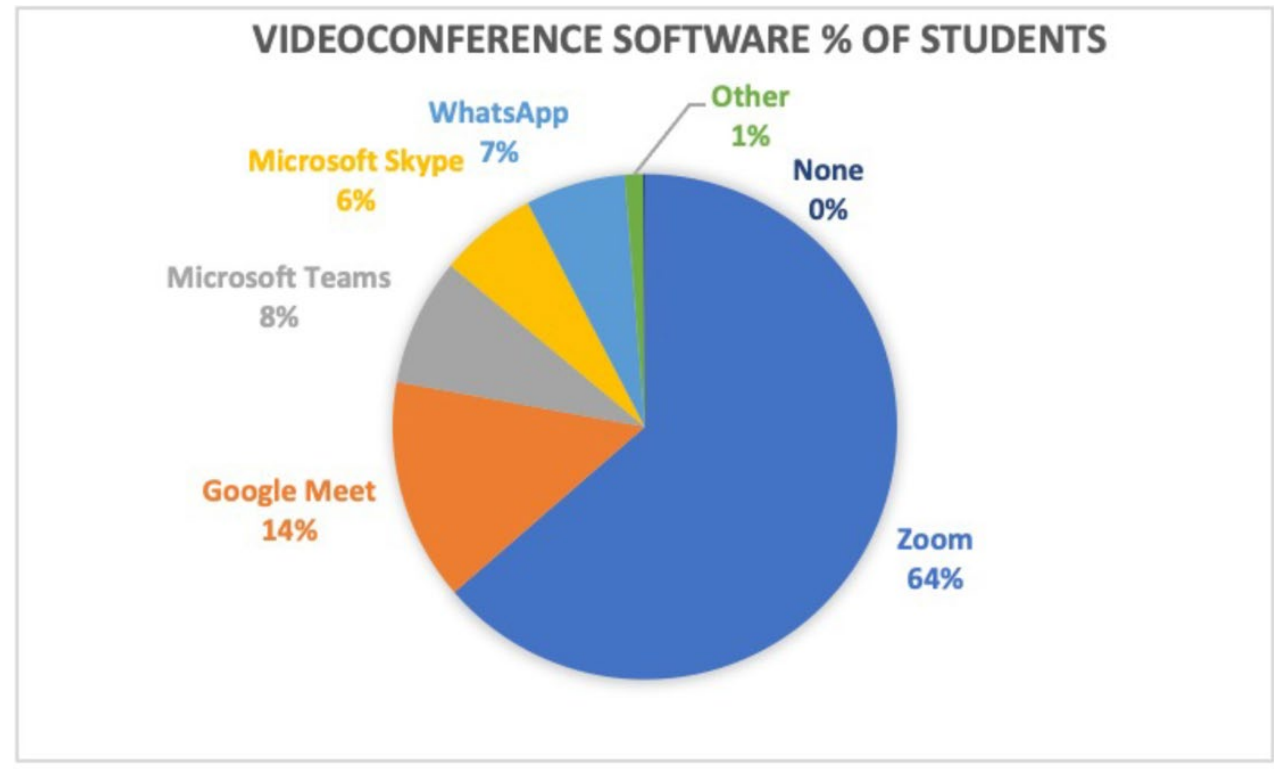

Fig. 9. Video meeting method used from the student point of view

After going through a semester online, the board of directors of the University of Petroșani did not select a unique software for meeting conferences at the beginning of the academic year 2020/20221. This situation led to an unpleasant situation, so students were forced to use a different meeting solution for online courses. More than $64 \%$ of students say they participate in online courses organized by the Zoom meeting solution. It is important to say that the other meeting solution was also used.

\section{HOMEWORK TRANSMISSION\% OF STUDENTS}

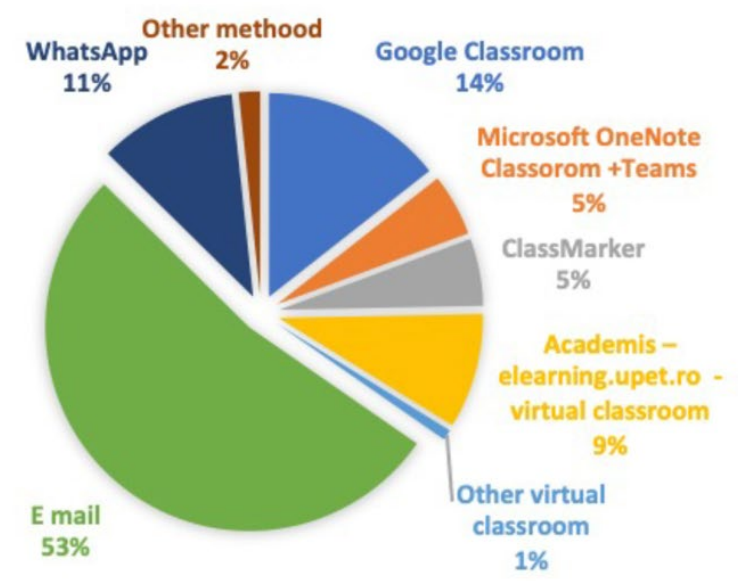

Fig. 10. Homework or projects transmission method used from the student point of view

And because the global prospect of ending the pandemic was distant, for the autumn semester of the academic year 2020/2021, the University of Petroșani has implemented an eLearning platform. This platform called Academis proved to be incomplete, the main 
disadvantage being the lack of the online meeting module. Unfortunately, this was not the only weakness. Students were required to submit homework or project to use mainly e-mail, at $53 \%$. Only $9 \%$ of university students used the new implemented platform. Even WhatsApp is a common solution for students.

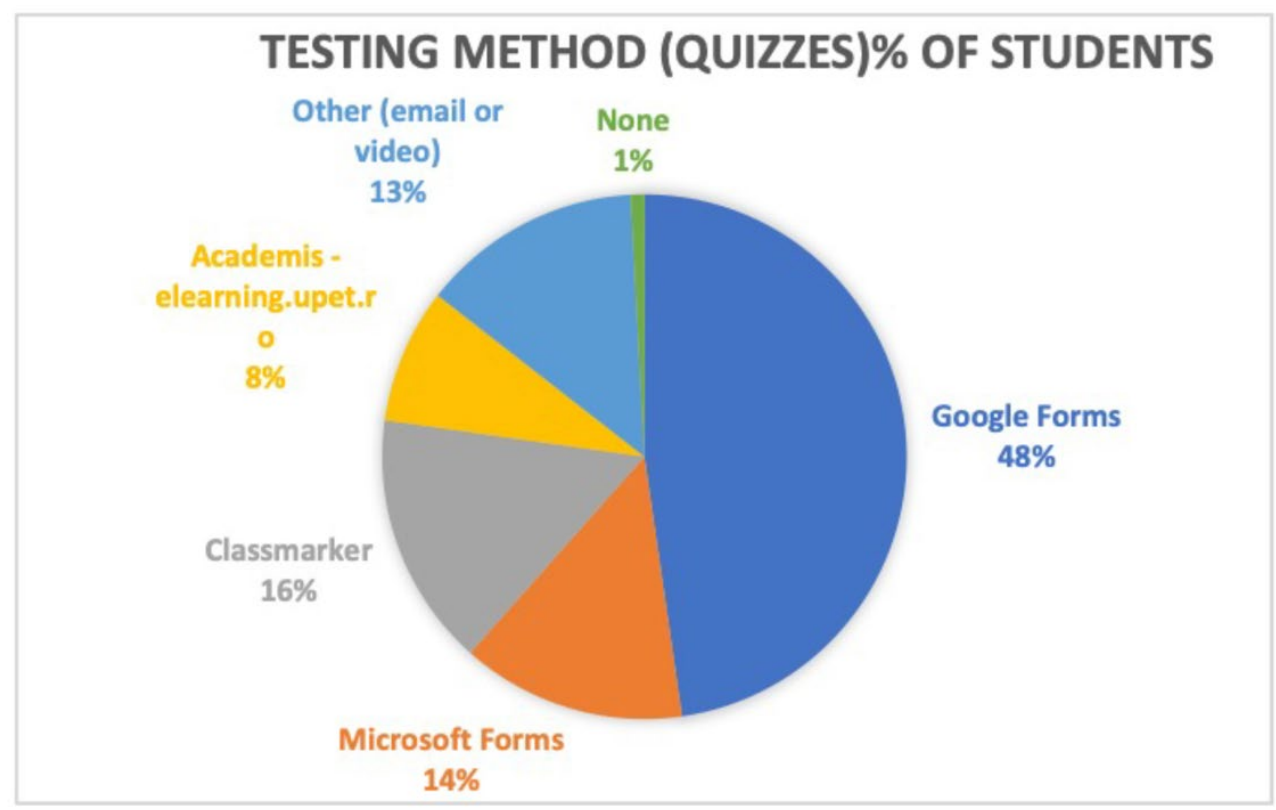

Fig. 11. Testing method used from the student point of view

Quizzes have been widely used as a testing method. $86 \%$ of students perceived it as the most used examination method. Teachers have resorted to various forms of testing such as Google, Class Marker or Microsoft. Surprisingly, $13 \%$ of students mention homework or emailing as a method of assessing topics.

\subsection{Statistical analysis}

Using the teacher point of view versus the student point of view for the University of Petroşani via the teaching method used, the statistical analyses was made as a benchmark testing.

The authors in their analysis noticed that there was a very strong link between the perspectives of the parties, the teachers versus the perspective of the students. It looked at the online teaching meeting methods used (with a significance of the correlation $\mathrm{R}=0.986>0.63$ for 5 degrees of freedom as Zoom, G. Meet, M. Teams, M Skype, WhatsApp, Others). Test F also produces a high value $(177,677)$, and Sig. the corresponding F statistic is $0.000(0.00)$, which indicates a significant linear relationship between two variables. You can conclude that the results are not accidental, because both $\mathrm{F}$ are large and the significance of Sig. is low. The regression coefficient $\mathrm{R}=0.986$ shows a strong link between the variable number of students and the independent variable number of teachers. The model explains $97.3 \%$ of the total variation of the variable $(\mathrm{R} 2=0.973)$. The remaining $2.7 \%$ is due to other residual factors that are not included in the model. This comparative view proves that the teaching methods proposed by the teachers were validated by the students' options, so that the teaching methods proposed by the teachers are perfectly received by the students of the University of Petroșani. 
Table 1. Regression analysis of and correlation between perspective of teachers and students over online meeting methods.

\begin{tabular}{|c|c|c|c|c|c|c|c|}
\hline \multicolumn{6}{|c|}{ Model Summary } & & \\
\hline Model & $\mathrm{R}$ & R Square & \multicolumn{2}{|c|}{$\begin{array}{c}\text { Adjusted R } \\
\text { Square }\end{array}$} & $\begin{array}{l}\text { Std. Error of } \\
\text { the Estimate }\end{array}$ & & \\
\hline 1 & $0,986^{\mathrm{a}}$ & 0,973 & & 0,967 & 34,606 & & \\
\hline \multicolumn{8}{|c|}{ a. Predictors: (Constant), No of teachers } \\
\hline \multicolumn{8}{|c|}{$\begin{array}{ll}\text { ANOVA }^{\mathrm{a}} \\
\end{array}$} \\
\hline \multicolumn{2}{|c|}{ Model } & \multicolumn{2}{|c|}{ Sum of Squares } & df & Mean Square & $\mathrm{F}$ & Sig. \\
\hline \multirow[t]{3}{*}{1} & Regression & \multicolumn{2}{|c|}{212787,670} & 1 & 212787,670 & 177,677 & $0,000^{\mathrm{b}}$ \\
\hline & Residual & \multicolumn{2}{|c|}{5988,045} & 5 & 1197,609 & & \\
\hline & Total & \multicolumn{2}{|c|}{218775,714} & 6 & & & \\
\hline \multicolumn{8}{|c|}{ a. Dependent Variable: No_of_students } \\
\hline \multicolumn{8}{|c|}{ b. Predictors: (Constant), No of teachers } \\
\hline
\end{tabular}

Comparative analysis of online tools, such as meeting tools, projects or homework, proves the links and correlations. These methods proposed by teachers are validated by students in $98 \%$ for meeting tools and $99 \%$ for project submission methods. Regarding the testing method there are differences, the methods proposed by teachers are validated by students only in proportion of $76 \%$. The cause may be because students did not correctly perceive the video conferencing exam method combined with the Quizzes exam method, such as a single method.

\section{Discussion and Conclusions}

In the academic field despite the primary and secondary education the email is a very used and efficient tool for communication online. In fact, only the favourite meeting tool for the University of Petroşani members, Zoom, has a similar reliance for students. It is also relevant that Facebook groups or other social media tools, used mostly by students and teachers before pandemic for communication, has dramatically drop down in their preference.

The summary conclusion of the paper is that online education methods and tools have been very well accepted by the teachers and students as well but using different tools for each component of the online teaching, respective meeting solutions, virtual classrooms or testing methods are not favourable for the students. Using more than tree methods for all the online elements, such as teaching, projects or testing are difficult to accept for both students and teachers.

In the 2013 year the authors implement at the University of Petroșani the Microsoft Office 365 A1 collaborative platform, and then Eduard Edelhauser proposed in 2018 year as management vice rector and as a project manager, to implement a storage platform as a virtual library. Both tools are relatively difficult accepted by the university management, and one year ago at the beginning of the pandemic, the management had made two huge mistakes in the field of online education. First in the academic year 2019/2020 they did not implement the existing Microsoft Office 365 A1 platform that offers all the collaborative and online tools. Second in the academic year 2020/2021 they implement a pour and rudimentary eLearning platform called Academis. This platform does not offer a meeting instrument, has a pour developed testing tool, so it was used only by a small number of students, in fact 8$9 \%$ have used this platform.

The authors have demonstrated as an example of good practice, how two use a professional collaborative software for online education, during the 2020 year, by creating more than 750 institutional accounts@upet.ro, a Microsoft account, for a quarter of the University of Petroșani students, more than 20 virtual classes with teaching materials, 
homework section and quizzes in Microsoft Office 365, for their students and their POCU 122596 European project.

Today, after more than a year of online learning, thanks to the personal teacher effort, the teaching process can be considered as acceptable. The authors propose to implement a collaborative platform for the probably future hybrid education system, and the authors proposed the Microsoft solution being the safest solution and also the most used solution in the Romanian academic system.

\section{References}

1. Eduard Edelhauser, Lucian Lupu Dima, Virtual Education, a Challenge for the Management of the Romanian Universities, Proceedings of the $7^{\text {th }}$ Review of Management and Economic Engineering International Management Conference, „Management Challenges Within Globalization", $17^{\text {th }}-19^{\text {nd }}$ of September 2020, Technical University of Cluj-Napoca, România, Todesco Publishing House 2020, ISSN 2247 - 8639, pp 248-256, http://conference.rmee.org/wp-content/uploads/2020/10/Proceedings_RMEE2020.pdf

2. Edelhauser Eduard, Ionică Andreea, Lupu-Dima Lucian, A Business Intelligence Software Made in Romania, a Solution for Romanian Companies During the Economic Crisis, Proceeding of the MS'10 International Conference, Computational Intelligence in Business and Economics, 15-17 July 2010, Barcelona, Spain, pp. 247-254

3. Eduard Edelhauser, Lucian Lupu - Dima, Management Information Systems. Past and Present in Romanian Organisations, The $11^{\text {th }}$ International Conference on Informatics in Economy, Education, Research \& Business Technologies (IE 2012), 10-11 May, 2012, Romania

4. Sevilla, G., Zoom vs. Microsoft Teams vs. Google Meet: Which Top Videoconferencing App Is Best, Available online: https://www.pcmag.com/news/zoom-vs-microsoft-teams-vsgoogle-meet-a-videoconferencing-face-off (accessed on 24 February 2021)

5. Gary Chesnutis, Zoom a Leader in 2020 Gartner Magic Quadrant for Meeting Solutions \& UCaaS, Worldwide, Available online: https://blog.zoom.us/zoom-leader-2020-gartnermagic-quadrant-for-meeting-solutions-ucaas/ (accessed on 24 February 2021) 